\title{
COMÉRCIO E ESPAÇO COLETIVO NO CALABAR
}

COMERCIO Y ESPACIO COLECTIVO EN CALABAR

\section{TRADE AND PUBLIC SHARED SPACE IN CALABAR}

\section{GONÇALVES, THAIIS}

Arquiteta,especialista em Assistência Técnica em Habitação e Direito à Cidade pela Residência Técnica em Arquitetura, Urbanismo e Engenharia da Universidade Federal da Bahia, especialista em Direito Urbanístico e Ambiental pela PUC Minas, Mestranda em Arquitetura e Urbanismo pela Universidade Presbiteriana Mackenzie. E-mail: thaisalesg@gmail.com

\section{TAHARA, AKEMI}

Arquiteta, mestre em Arquitetura pelo Dept. de Arquitetura na Universidade de Mie - Japão, especialista em Conforto Ambiental e Sustentabilidade pela Faculdade de Ciências Exatas e Tecnológicas, professora e doutoranda na Faculdade de Arquitetura e Urbanismo da Universidade Federal da Bahia. E-mail: akemi.tahara@ufba.br

\section{RESUMO EXPANDIDO}

O Calabar é uma comunidade habitada por aproximadamente 20 mil pessoas, incluindo a favela Alto das Pombas, em mais de 5.300 domicílios (IBGE, 2000), localizada em um vale, entre dois bairros privilegiados de Salvador: Barra e Ondina. Segundo o Plano Diretor de Desenvolvimento Urbano (2008), é uma Zona Especial de Interesse Social do tipo I (ZEIS I).

Embora já tenha sofrido algumas intervenções públicas, a comunidade ainda não dispõe de uma infraestrutura adequada de saneamento ambiental: o abastecimento de água atende a quase toda a comunidade, mas apresenta deficiências: as redes de drenagem de águas pluviais e de esgoto sanitário encontram-se, quando não danificadas, em estado precário de conservação; há pontos de acúmulo de resíduos sólidos e vias sem varrição ou coleta regular (MORAES, 2007). Já sobre os equipamentos público-comunitários, estes existem, mas não atendem em número e qualidade a todos os moradores, a saber: Posto de Saúde da Família; Escola Pública; Praça/Largo; campo de futebol; centro comunitário, biblioteca e ONG.

O Calabar, portanto, como diversos assentamentos informais das cidades brasileiras, ainda necessita de intervenções de caráter urbanístico, ambiental, habitacional e de regularização fundiária. Neste trabalho, com base no Trabalho de Conclusão de Curso de Especialização em Assistência Técnica, Habitação e Direito à Cidade da Universidade Federal da Bahia (GONÇALVES, 2015), optou-se por desenvolver um projeto urbanístico que tivesse como fio condutor a busca por espaços públicos de convívio dentro do Calabar, reforçando a importância da melhoria dos espaços públicos coletivos em ocupações informais. ${ }^{1}$

Além dos problemas de habitabilidade (salubridade, iluminação, ventilação, problemas estruturais da construção) recorrentes nas moradias de assentamentos informais, a alta densidade de ocupação desordenada gera também problemas ambientais e urbanos, bem como problemas de vizinhança. Assim, além de prestar assistência técnica para questões referentes à habitação, é necessário também tratar os espaços "públicos", os locais de uso coletivo da comunidade, uma vez que estes são objeto de maior negligência por parte da própria população, que se preocupa em cuidar da porta de suas casas para dentro, ou por parte do poder público, geralmente ausente nesses locais.

O Calabar é uma ocupação informal bastante adensada. As atividades de assistência técnica desenvolvidas pelo Consultório de Arquitetura e Engenharia, no âmbito da Residência AU+E/UFBA, permitiram percorrer ruas, vielas e becos a caminho das casas de diversos moradores e perceber que há pouquíssimos, quase insignificantes, espaços ainda livres (não ocupados) na Comunidade. A maioria deles são espaços que restam da ocupação irregular das construções e permanecem ali até que algum "projeto" os defina como área efetivamente pública (espaço público de uso coletivo) ou até que alguém venha e os ocupe com mais uma construção irregular, tornando-o "privado". 
As áreas públicas existentes no Calabar, sejam elas ruas, becos, largos, praças ou calçadas, geralmente não se mostram de boa qualidade por possuírem deficiências na distribuição dos espaços, nas dimensões necessárias, na qualidade dos materiais, nas questões de drenagem e de acessibilidade. Esses espaços deveriam ser tratados com a importância devida, respeitando seus usuários e proporcionando-Ihes qualidade de vida.

A falta de áreas livres relevantes no interior do assentamento dificulta a proposição de novos espaços de uso coletivo, pois não há onde alocá-los. Assim, é necessário encontrar nos espaços já ocupados uma forma de reinventá-los, de recriá-los para abrigarem novos usos e aprimorar os que já existem, sendo ocupados de novas maneiras.

A qualidade de vida de uma cidade é, e sempre será, medida pela dimensão da vida coletiva que é expressa nos seus espaços públicos dispostos democraticamente pela cidade, seja no parque, na praça, na praia ou mesmo na rua. O espaço público de uma cidade é o lugar do lazer, do descanso, da conversa corriqueira, da livre circulação, da troca e, sobretudo, da possibilidade do encontro com o outro.

[...]

É importante lembrar que não basta projetar uma praça ou um parque. É preciso entender a dinâmica de uma cidade e a vida das pessoas no seu cotidiano, a fim de que os espaços públicos a serem projetados reflitam as necessidades e os anseios dos seus usuários, para só assim serem realmente utilizados. Um bom projeto de espaço público não depende apenas de uma boa execução técnica; também deve ser o espaço certo, no lugar certo e para as pessoas certas (GATTI, 2013, pp.8-9).

Essa percepção de espaço público conduziu a busca por áreas ainda livres existentes na comunidade do Calabar, a fim de criar um bom projeto para uso coletivo que atendesse a uma demanda real e se adequasse à dinâmica da vida local, potencializando o uso do lugar e promovendo a convivência saudável entre todos os seus usuários.

Ao longo dos oito meses de realização do Consultório de Arquitetura e Engenharia, aproveitando as oportunidades de contato direto com os moradores e as caminhadas pelo bairro, foi possível identificar alguns pequenos espaços livres ainda existentes no Calabar e algumas áreas relevantes para desenvolver projetos de melhoria de espaços públicos/coletivos. De todos esses espaços identificados, 2 foram escolhidos como "Áreas de interesse", objetivando fechar um perímetro de intervenção para que, dentro deste perímetro, pudessem ser pensadas propostas mais concretas de projeto.

A área de intervenção escolhida possui a essência de um espaço público, uma vez que alberga usos diversos, como comércio, serviço e habitação. Por esta razão é também um local por onde se cruzam muitos fluxos: pessoas, carros, bicicletas; jovens, adultos, idosos. É área de encontro, e é área de conflito. É área de todo mundo. Possui problemas recorrentes de drenagem e acessibilidade. As diversas atividades nela desenvolvidas necessitam de uma certa organização para que coexistam em harmonia. (ver Figura 1)

A proposta de intervenção visou qualificar duas áreas de interesse identificadas e melhorar a conexão entre elas a fim de que esses espaços coletivos proporcionem o estar, o lazer e o circular de forma segura e agradável. $O$ projeto principal consiste na reforma para padronização e melhoria das unidades comerciais existentes (área de interesse 1), com intuito de criar um espaço coletivo ampliado e de qualidade sobre as mesmas. Essa ideia de projeto surgiu da percepção de que as unidades comerciais, dispostas de forma nãopadronizada, não permitem o aproveitamento de suas coberturas, e de que a rua que passa atrás delas (Av. Maria Pinho), numa cota mais alta, possui potencial para espaço público, uma vez que permite uma grande visual do entorno e do largo em sua frente (ver figuras 2 e 3 ).

A sugestão para o uso do lugar é que as unidades de comércio reformadas possam funcionar como equipamento público de comércio, a exemplo dos mercados públicos municipais: os comerciantes locam a unidade comercial da prefeitura, que fica responsável pela administração. 
Figura 1: Mapeamento e caracterização da área de intervenção.

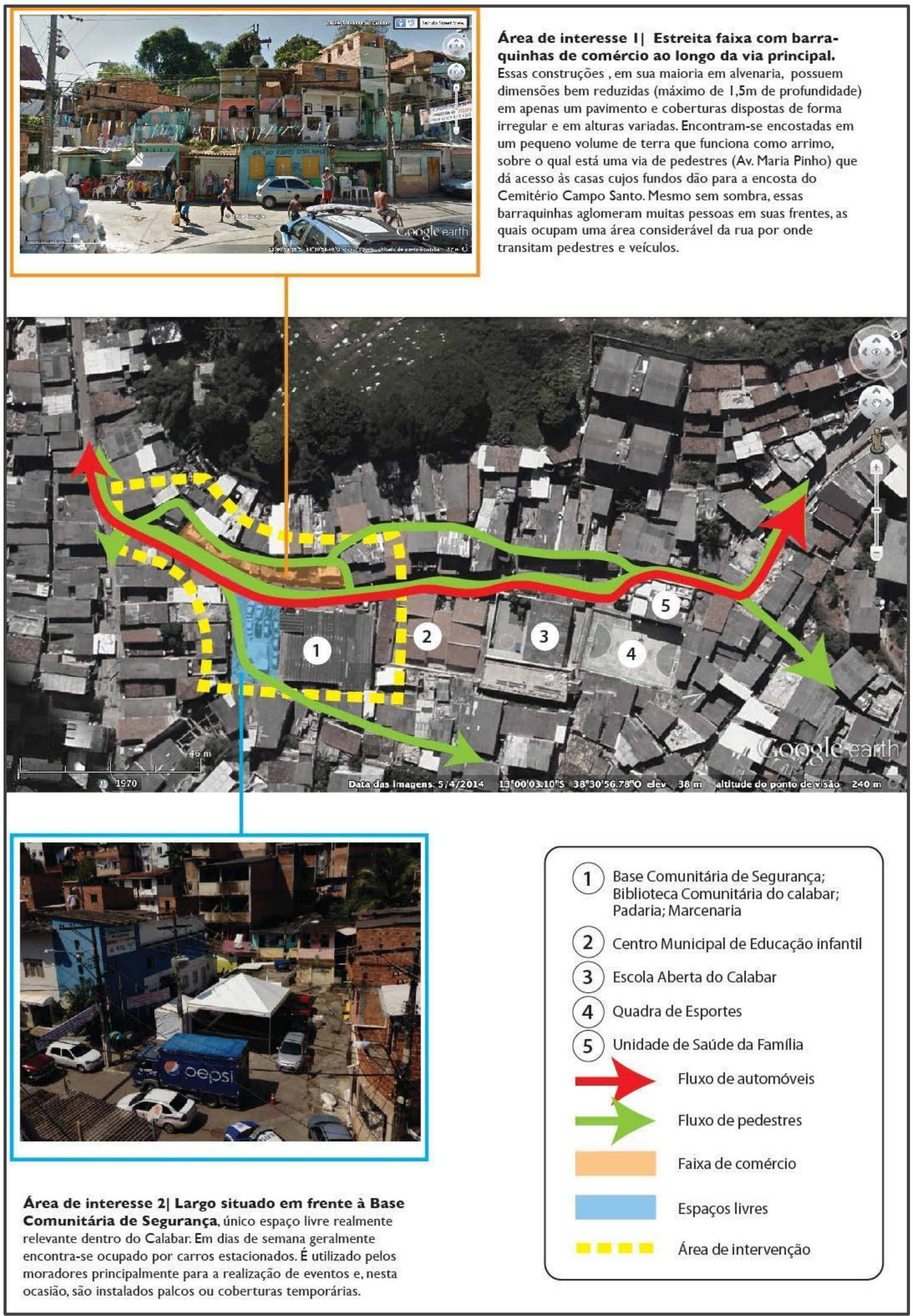

Fonte: GONÇALVES, 2015. 
Figura 2: Corte da situação atual.

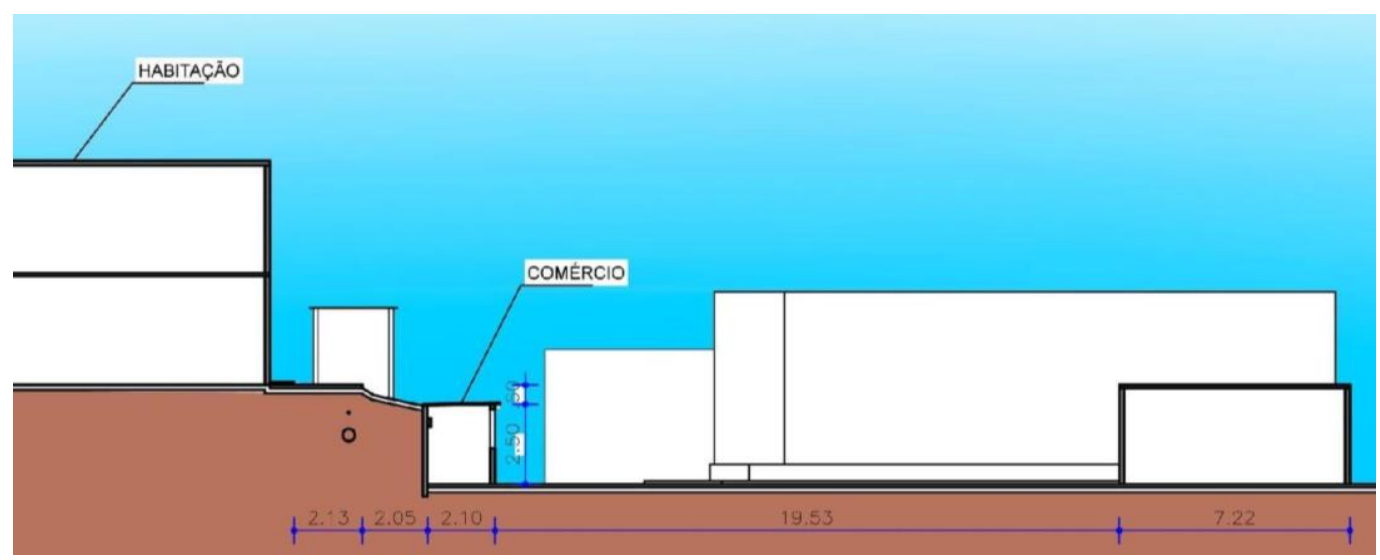

Fonte: GONÇALVES, 2015.

Figura 3: Situação proposta.

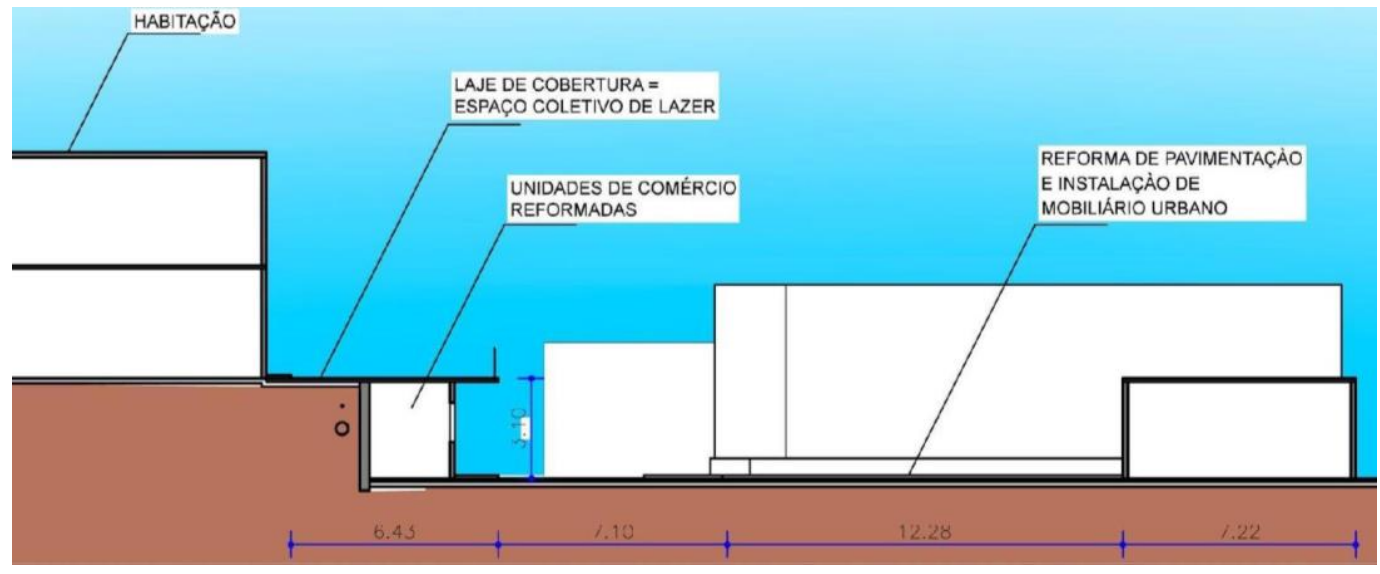

Fonte: GONÇALVES, 2015.

Para a elaboração do projeto, foi realizada uma pesquisa com os ocupantes das unidades a fim de conhecer o tipo de comércio desenvolvido, qual a sua dinâmica de funcionamento e quais as necessidades e as expectativas dos usuários para a melhoria do espaço em questão. A pesquisa consistiu na aplicação, pela autora, de um questionário diretamente aos comerciantes e, nessa ocasião, foi pedida permissão para que se tirassem fotos e medidas gerais para cadastro aproximado de cada unidade. Alguns comerciantes não estavam presentes, portanto, alguns questionários não foram preenchidos, mesmo assim, suas unidades puderam ser medidas por fora. O levantamento cadastral da área de entorno também foi realizado pela própria autora, contando com a ajuda dos demais residentes da equipe.

Com o cadastro das unidades comerciais e seu entorno, tinha-se o ponto de partida para elaborar uma proposta compatível com a necessidade dos usuários do espaço, que atendesse às demandas por melhoria, oferecendo mais área e qualidade espacial.

$\mathrm{Na}$ Oficina Direito à Cidade, promovida pela equipe com os moradores, algumas questões discutidas mostraram demandas importantes para os espaços públicos do local e contribuíram para orientar a elaboração do projeto.

Unindo o que foi analisado na aplicação dos questionários de pesquisa e as discussões levantadas na referida oficina, foi possível elencar as seguintes demandas:

- Unidades comerciais: 1) Mais espaço, mais profundidade; 2) Cobertura para proteger da chuva; 3) Banheiro

- Av. Maria Pinho (Rua de cima): 1) Acessibilidade; 2) Drenagem; 3) Alargamento da rua; 4) Conter a ocupação das casas em direção à rua; 5) Voltar a ser espaço de convívio e diversão.

O projeto visou promover a melhoria da qualidade dos espaços coletivos ("públicos") existentes no Calabar, propondo um espaço de convívio para seus moradores, em meio ao tecido urbano já bastante adensado e consolidado desta comunidade, que não possui áreas livres relevantes. Teve como objetivos específicos: 
- Aproveitar o desnível entre a Av. Maria Pinho e a 1 $1^{\text {a }}$ Travessa do Calabar para criar uma laje de uso coletivo que funcione como cobertura para as unidades comerciais reformadas;

- Padronizar e melhorar o espaço das unidades comerciais existentes (mais área, mais profundidade), deixando áreas livres para convívio;

- Promover a acessibilidade à Av. Maria Pinho (rua de cima) e às unidades de comércio, melhorando a integração destas com o largo defronte;

- Complementar a infraestrutura urbana através da drenagem de águas pluviais e da pavimentação, organizando a circulação de veículos e pedestres, tomando como prioridade a circulação de pedestres.

Para isso, o projeto propõe a reforma e padronização das 12 unidades comerciais existentes na $1 \mathrm{~A}$ Travessa do Calabar, incluindo a reforma do largo defronte, onde atualmente (2015) se localiza a Base Comunitária de Segurança.

O programa de necessidades consiste em 12 unidades comerciais, contendo 3 tamanhos diferentes: 4 módulos (A) de $5,40 \mathrm{~m}^{2} ; 5$ módulos (B) de $6,84 \mathrm{~m}^{2} ; 3$ módulos (C) de $8,28 \mathrm{~m}^{2}$. Prezou-se pela acessibilidade através da rampa como principal elemento de circulação vertical e do banheiro acessível para portadores de necessidades especiais. Para a reforma do largo, optou-se por: mudança de pavimentação para priorizar a circulação de pedestres em detrimento de automóveis; utilização de elementos de "traffic calm"; plantio de vegetação de médio porte, instalação de paraciclo e mobiliário urbano (bancos e lixeiras).

Figura 4: Perspectivas do projeto "Comércio e espaço coletivo no Calabar".
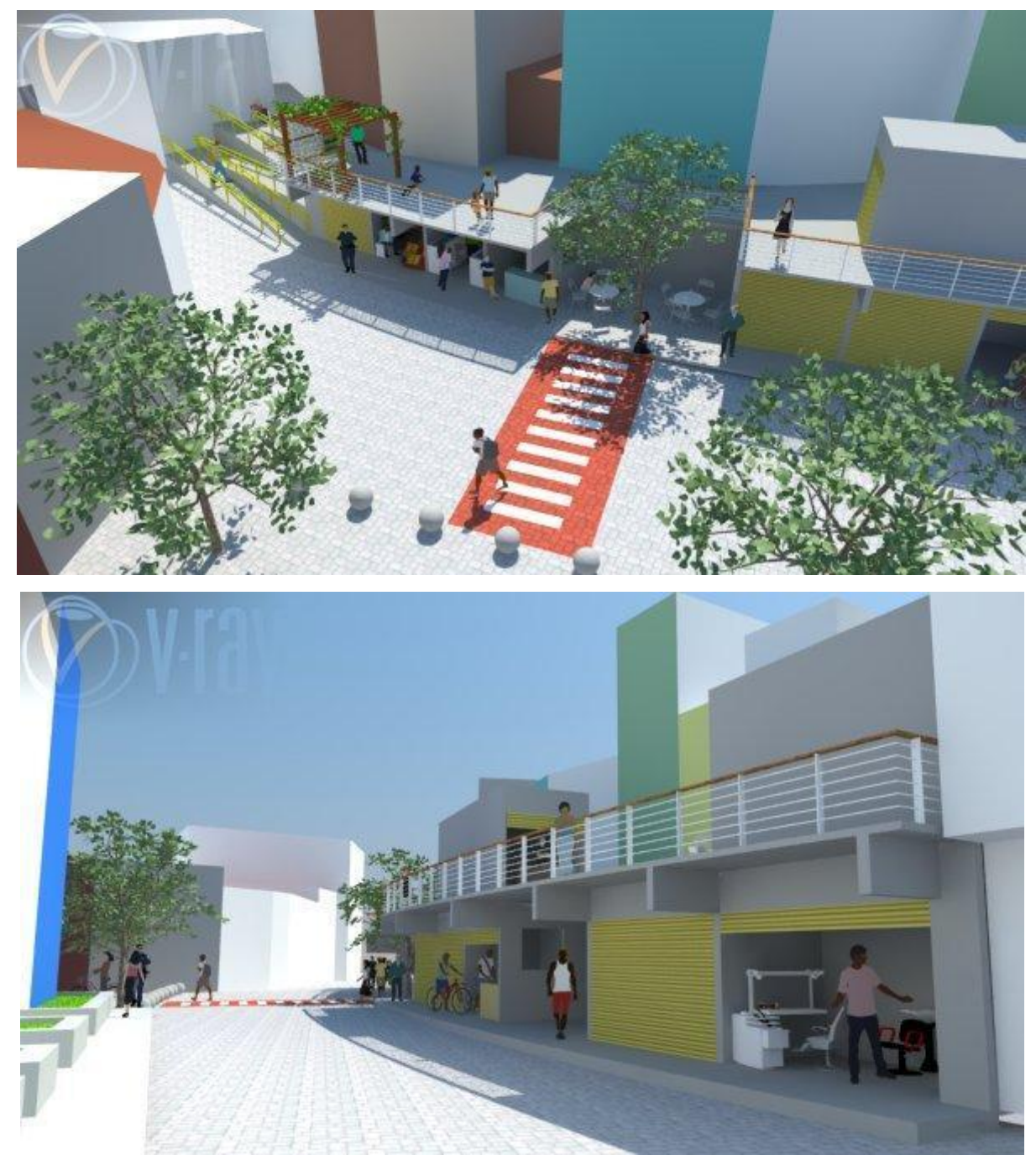

Fonte: GONÇALVES, 2015.

A proposta foi apresentada aos moradores da comunidade em uma reunião na Biblioteca Comunitária do Calabar. Os que compareceram posicionaram-se a favor do projeto, demonstrando zelo pelo lugar e interesse por vê-lo melhorar. 
Foi importante perceber como uma proposta de melhoria de um espaço de uso coletivo gera boas expectativas e entusiasmo na população, ao mesmo tempo em que causa preocupação pela falta de cuidado e de controle de sua utilização por todos, uma vez que se trata de um espaço democrático, o qual deve permitir que qualquer pessoa, geralmente em qualquer horário, sirva-se dele. Os moradores demonstraram a necessidade de resguardar-se dos conflitos de vizinhança tão recorrentes nas ocupações informais. Isso dificultou a aceitação unânime de algumas propostas do projeto, a exemplo da previsão de uso de algumas unidades como bar, que podem causar barulho e outros tipos de desconforto para as moradias do entorno imediato, as quais de fato encontram-se bastante próximas devido ao adensamento das construções.

A partir da dificuldade de encontrar espaços livres para desenvolver uma proposta de projeto, identificar uma demanda real através da observação desses espaços e suas dinâmicas de uso foi fundamental para comprovar a necessidade da existência de intervenções como essas. A ausência de áreas de lazer, de esporte e de convivência, adequadas para a população é notória, porém, acaba tornando-se "normal" e aceitável pelos moradores, que, acostumados à negligência do poder público, reforçam essa falta de cuidado através de soluções individuais e atitudes egoístas que desconsideram a totalidade do território e de seus usuários.

O investimento em projetos de qualidade para áreas públicas é, sem dúvida, um fator que desenvolve o senso de comunidade da população, assim como o sentido de pertencimento, que alimenta o zelo pelo lugar comum.

\section{REFERÊNCIAS}

CONCEIÇÃO, F. Cala a boca Calabar: a luta política dos favelados. Petrópolis: Editora Vozes, 1984.

GIUDICE; SOUZA. O processo recente de favelização em Salvador: o exemplo do Calabar. RDE - Revista de Desenvolvimento Econômico, Salvador, Ano II, nํ3, jan. 2000.

MORAES, L. R. S. Avaliação e Proposição de Ações de Saneamento Ambiental em área periurbana: um esforço com uso de metodologia participativa na comunidade do Calabar, Salvador. In: 24 Congresso Brasileiro de Engenharia Sanitária e Ambiental, 2007.

SALVADOR. Secretaria Municipal de Habitação. Regularização fundiária sustentável das áreas de Calabar/Alto das Pombas, Gamboa/Unhão, Canabrava e Narandiba. Salvador: Comissão setorial permanente de licitação, 2006.

GATTI, S. Espaços Públicos. Diagnóstico e metodologia de projeto. São Paulo: ABCP, 2013.

GONÇALVES, T. S. Comércio e Espaço Coletivo no Calabar. Trabalho Final apresentado ao Curso de Especialização Assistência Técnica em Habitação e Direito à Cidade. Programa de Pós-Graduação em Arquitetura e Urbanismo da Universidade Federal da Bahia, Salvador, janeiro de 2015.

\footnotetext{
NOTAS

${ }^{1}$ A autora integrou a 1a․ edição deste curso (2013/14), na modalidade Residência Profissional em Arquitetura, Urbanismo e Engenharia, implantada pela Universidade Federal da Bahia (Residência AU+E/UFBA), tendo como tutora a Profa. Akemi Tahara. Desenvolveu as suas atividades práticas na Comunidade do Calabar, no período de fevereiro a outubro de 2014, integrante de uma equipe de cinco Residentes atuantes na mesma área, além da autora, Adelaide Cristina Luna, Constança Gabriela Castro, Paolo Pellegrino, e Stefano Pisano, os quais também desenvolveram individualmente seus Trabalhos de Conclusão para essa comunidade.
}

NOTA DO EDITOR $\left(^{*}\right)$ O conteúdo do artigo e as imagens nele publicadas são de responsabilidade do(s) autor(es). 